\title{
PERCEPTIONS OF COMMUNITY LEADERS AND THE MERGER OF RURAL HEALTH SERVICES
}

\author{
Dean G. Smith, Ph.D., \\ Howard S. Zuckerman, Ph.D.
}

\begin{abstract}
The merger of rural primary care and home health services offers the potential of increasing the administrative efficiency of health care, and thereby enhancing quality of care and increasing access to services, particularly health promotion. In a merger of rural health services in Northeastern Vermont, a survey of key community leaders revealed that improved organization of services, improved health status and greater accessibility of services were benefits expected and to some extent realized as a result of the merger process. The desire to preserve community-based services and having a common philosophy were important factors which served to initiate the merger. The actions of a few key individuals and the support of involved organizations were instrumental in continuing the process.
\end{abstract}

\section{INTRODUCTION}

In an evaluation of a merger of rural health centers in Northeastern Vermont with a home health agency, a survey of community leaders was conducted to examine their support, resistance and perceptions of the merger. This paper reports the results of this survey and discusses the implications for the role of community leaders in rural health services. To put this evaluation in context, we first discuss briefly some illustrations of changes in the organizational structure of rural health facilities, and then consider the importance of key community leaders to such organizational changes.

The involvement and support of community leaders can be an

\footnotetext{
Dr. Smith is an Assistant Professor, Department of Health Services Management and Policy, The University of Michigan School of Public Health.

Dr. Zuckerman is an Associate Professor, Department of Health Services Management and Policy, The University of Michigan School of Public Health. RAD).

This study was supported by a grant from the W.K. Kellogg Foundation (UHG0001L/

Requests for reprints should be addressed to Dean G. Smith, Department of Health Services Management and Policy, The University of Michigan School of Public Health, Ann Arbor, Michigan 48109-2029.
} 
important dimension to the success of a rural health center, particulary when contemplating or undergoing organizational change. The role of community leaders' support in adapting to a competitive health care environment is seen as being important, and may be even more crucial in merger situations. ${ }^{1.2}$ Successful mergers of health services are processes which take time and involve cooperation from several parties. Community leaders may help or hinder the merger process.

\section{Organizational Change and Mergers}

The organization of rural primary health clinics has been studied and classified as part of the National Evaluation of Rural Primary Care Programs., Almost half of the rural health centers changed their organizational structures in some way during the two-year evaluation. While many changes only involved the loss or gain of a physician, the sheer number of changes is sufficient to indicate the dynamic environment of rural health.

Prindaville, Sidwell and Milner suggest that having an opportunity is an important prerequisite to successfully integrating programs. ${ }^{5}$ Starkweather presents a more specific proposition that mergers are more likely when both organizations "face crises." In the case to be reported, while neither the financial difficulties of the health centers nor the search for new leadership at the home health agency may have been crises, they certainly presented an opportunity for the organizations to consider consolidation.

More directly related to the case at hand, the strategic factors involved with integrating hospice and home health services are: similar types of patient needs, potential for sharing provider and administrative staff, joint referral networks and common cost containment strategies." Hospice and home health services were previously integrated within the home health care agency examined below. One hope for the merger of home health and health centers was to expand this type of service integration.

As a second example of combining rural health services, the 1978 Mental Health Initiative provided supplemental funding to establish ties between primary care programs and mental health centers. ${ }^{5}$ The goals of this program were to increase access to mental health services and to reduce the fragmentation of services. Among the identified keys to success were organizational strategies which included philosophical compatibility and effective communication. 


\section{Community Leaders' Support and Satisfaction}

The importance of community leaders' satisfaction has received a good deal of attention in the literature. In fact, satisfaction of key community leaders has been identified as one of the four major approaches to assessing organizational effectiveness. ${ }^{7}$ Community leaders, stakeholders and strategic constituencies are variously defined as individuals or groups with a stake in the organization's products or services, producers of organizational output, groups whose compensation is essential for organizational survival, or those whose lives are significantly affected by the organization. Effectiveness is determined by the extent to which the organization responds to demands and expectations, which may be conflicting, of external and internal key community leaders.

The involvement and support of key stakeholders can be an important dimension to the success of an organization, and such support may be particularly important in a time of significant environmental and organizational change. Community leaders' support has been found to be critical for organizational adaptation to a competitive environment and even more important in merger situations. ${ }^{1.2}$

Applying lessons from hospitals and their various constituencies to rural organizations, it has been found that rural health centers and home health agencies are both community-oriented and dependent on their communities both socially and financially. Previous studies of rural health centers have also indicated that community support plays an important role. In a study of a rural health system in New Mexico, some management implications were that successful integration requires innovation and cooperation of community members. ${ }^{8}$ A detailed study of nine RHI sites identified management and community factors related to financial success. ${ }^{9}$ In addition to general management expertise and good locations, good community relations were associated with financial viability. Finally, a study of RHI sites in Mississippi recommended that RHI sites trying to increase utilization should provide more information to the community and to participate in public activities, actions which would strengthen ties to community leaders. ${ }^{10}$

In the case to be reported, an appropriately important concern was the perception of key community leaders concerning the merger, and the potential impact of these community leaders on the merger. Successful mergers of health services organizations typically are processes which take a long time and require cooperation from various constituencies. Assessment of the perceptions of community leaders was 
therefore seen as a significant factor in evaluating the success of the merger of several rural health facilities.

\section{Background}

Northern Counties Health Centers was formed in 1976 under the Rural Health Initiative (RHI; P.L. 94-63, 1975). The RHI is part of the community health centers program, on which the federal government spends over $\$ 400$ million to assist over 5 million people each year. The RHI provided initial funding for 47 rural health centers in its first year and now partially supports 488 rural health centers. ${ }^{.}$It is estimated that nearly one-fourth of all counties in the United States with some rural population have been affected by rural health centers. ${ }^{12}$

Initially, rural health centers were heavily dependent upon federal funding. However, this funding has become more restrictive, meaning that rural health centers have been required to become more selfsufficient. Nearly half of the rural health centers recently surveyed perceived worsened economic conditions, and even more indicated that their Public Health Service funding had been reduced, in many cases requiring cutbacks of services and personnel. ${ }^{13}$

In response to financial difficulties, many community health centers are seeking more stable sources of funding as an alternative to reducing services. Northern Counties Health Centers is no exception. During 1983-84, 75\% of a sample of community health centers expanded or initiated coordination of services with other organizations. ${ }^{14}$ Coordination of services for the elderly was cited as an area of particular promise due to the possibility of Medicare payment.

One possible source of coordination of services involves home health agency (HHA) services, which have been covered by Medicare since 1966. Reimbursement for HHA services was liberalized in 1981 with the removal of limits on visits and other restrictions. HHAs have additionally been shown to provide an opportunity for cost-savings and integration of health services. ${ }^{15}$

Northern Counties Health Centers, while exploring options for managing its financial concerns, undertook discussions with Caladonia Home Health Care Agency which was in the process of seeking new leadership and increasing services. On the basis of strategic plans supporting the concept, and initial willingness to pursue consolidation, an integration of rural primary health and home health services was proposed through a merger of these two organizations. This merger was supported financially through a demonstration grant from the W.K. 
Kellogg Foundation in 1986. As part of the grant, an evaluation was undertaken in order to assess the impact of the merger. An important part of the evaluation involved an assessment of the perceptions of community leaders.

\section{METHODS}

A questionnaire was designed to solicit key community leaders' impressions of the consolidation. Key community leaders were defined as persons who were either board members of one of the organizations or otherwise identified as a person with significant involvement in health care issues. The questionnaire was mailed to 101 key community leaders in March 1988. A follow-up survey was administered one year later.

The four-part questionnaire contained questions regarding the enabling forces, the implementation process, and the outcomes to date of the consolidation. The first set of questions addressed the extent to which various factors served as impetus for consolidation. The factors listed were based upon both general motivations for consolidations and some motivations which may be specific to rural health care organizations. General motivations given for mergers of health services were: reducing service duplication, organizational or system-wide financial constraints and consumer demands. The specific concerns given for rural health organizations were: preservation of the community basis of the services, the scarcity of personnel and the philosophy of each organization.

The second set of questions sought to identify how important several organizations and individuals were in initiating discussions about consolidation, and why they were important. Organizations listed include: the rural health centers, the home health agency, other home health and mental health agencies in the region, local hospitals and governmental agencies. It has been suggested that there may not be a clear consensus on influential persons in the community, and that a list of these persons may vary by issue. ${ }^{2}$ To address this concern individuals were not identified in the questionnaire-leaving responsibility for identification to the respondent.

Support and opposition to the consolidation of previously independent organizations was addressed by a third set of questions relating the extent to which listed groups helped or hindered the consolidation process. Management and board members of each organization listed in the second set of questions were included as well as local political, religious and secular organizations.

The fourth set of questions concerned the extent to which selected benefits were expected from the consolidation, and the extent to which these expectations had been met at that point in the process. Listed benefits were: improved organization of services, improved health status, more accessible or higher quality services and others. Respondents were also asked to identify any 
previously unforeseen problems or opportunities which they had observed. This fourth set of questions was asked again in the follow-up survey.

\section{RESULTS}

The survey respondents were divided into three groups on the basis of their organizational affiliation: health centers, home health care agency, or other affiliation. Response rates for both mailings were about $45 \%$, with similar rates by affiliation. About $61 \%$ of those responding to the initial survey also responded to the follow-up. Research on nonrespondents has indicated that they are less likely to be active in the sponsoring group both of which may reflect a lack of interest or knowledge about the topic of the questionnaire. ${ }^{16}$ While it is not possible to know if the perceptions of nonrespondents differed from those of respondents, responses received were generally consistent with conversations with many community leaders during two site visits.

Preservation of community-based services and common philosophy were identified as being factors serving to a great extent or a very great extent as impetuses for consolidation, (Table 1). Reducing service duplication was also highly rated. While recognizing the problems involved with interpreting multiple comparisons and the continuous nature of the rankings of factors, nevertheless these three factors were rated significantly higher than the other factors.

The need to make scarce personnel available area wide and organizational specific financial constraints were identified as factors which served to some extent. Rated somewhat lower were consumer demands for better service and restrictive reimbursement.

Increased competition, a factor which is frequently important in mergers of health care organizations was not rated as being an important factor. This result was not surprising in this case because of the monopoly situation which exists in this and many rural environments. ${ }^{17}$ Except for the community and county hospitals and a distant home health agency, these organizations, by design, do not have competitors.

The rural health centers and the home health agency involved in the merger were identified as the initiators of the consolidation discussions. Community hospitals and governmental agencies were identified as having had some role, although much less so than the merging organizations. A local home health agency and mental health agency, with which merger and joint venture had been discussed, and the county hospital were identified as having a minor role in the merger process. 


\section{TABLE 1}

Factors Serving as an Impetus for Consolidation

$$
(\mathrm{N}=46)
$$

\begin{tabular}{lcc}
\hline Factor $^{*}$ & Rating** & (Std.Dev.) \\
\hline Preservation of community-basis & 4.2 & $(0.9)$ \\
Common philosophy & 4.0 & $(0.9)$ \\
Reduce service duplication & 3.6 & $(1.2)$ \\
Scarce personnel & 3.0 & $(1.0)$ \\
Organization financial constraints & 2.9 & $(0.9)$ \\
Consumer demand for better service & 2.5 & $(1.1)$ \\
Restrictive reimbursement & 2.5 & $(0.9)$ \\
Consumer demand for lower prices & 2.3 & $(1.2)$ \\
Increased competition & 1.9 & $(0.9)$ \\
\hline
\end{tabular}

*Categories are not mutually exclusive.

**Responses were scaled from 1 ("Very little") to 5 ("Very great extent").

The patterns of impressions of support of the merger process are similar to patterns of organizations being important in the process. That is, measures of support are positively correlated with measures of involvement. There were no organizations identified as significantly opposing the merger. The management and boards of both organizations both helped the consolidation. Some respondents felt that a select few community leaders helped and most outside organizations were neutral. Only one respondent did not initially favor the merger; currently, all respondents favor the merger.

It was agreed that the health centers and home health care agency were the leaders in the consolidation. Other organizations had only minor roles and were neutral in their helping of the process. The health centers administrator was mentioned by $78 \%$ as being a key individual in the process. The home health care agency administrator was mentioned by $43 \%$, the chairman of the health centers board by $28 \%$, and others were mentioned by $11 \%$ or fewer persons. Concern over identification of influential persons was not warranted in this case.

Most persons expected some benefits from the merger in each of the categories (Table 2). Large benefits were expected only in terms of improved organization of services. Improved health status, higher quality of staff and care and making more services more accessible were also 


\section{TABLE 2}

Expectation and Realization of Benefits in the First Survey $(N=46)$ and the Follow-up Survey $(\mathrm{N}=47)$

\begin{tabular}{lccc}
\hline & & \multicolumn{2}{c}{ Extent of Realization } \\
\cline { 2 - 4 } Benefits $^{*}$ & & First & Follow-up \\
Expectation** & Survey*** & Survey*** \\
\hline Improved organization & 4.5 & 3.6 & 3.9 \\
of services & $(0.8)$ & $(1.1)$ & $(0.9)$ \\
Improved health status & 3.8 & 3.1 & 3.7 \\
in community & $(1.2)$ & $(1.3)$ & $(0.9)$ \\
Higher quality staff & 3.6 & 3.2 & 3.6 \\
& $(1.2)$ & $(1.2)$ & $(1.1)$ \\
Services more accessible & 3.6 & 2.9 & 3.7 \\
& $(1.2)$ & $(1.2)$ & $(0.9)$ \\
Higher quality care & 3.5 & 3.2 & 3.6 \\
& $(1.2)$ & $(1.2)$ & $(1.0)$ \\
More services available & 3.5 & 2.9 & 3.3 \\
& $(1.2)$ & $(1.1)$ & $(0.9)$ \\
Lower priced services & 2.7 & 2.3 & 2.3 \\
& $(1.2)$ & $(1.1)$ & $(0.9)$ \\
Average of All & 3.5 & 3.1 & 3.4 \\
& $(1.0)$ & $(1.0)$ & $(0.8)$ \\
\hline
\end{tabular}

* Categories are not mutually exclusive.

**Expectation responses were scaled from 1 ("No benefit") to 5 ("Large benefit").

***Realization responses were scaled from 1 ("Not met") to 5 ("Met in full").

expected as a result of the merger. Starkweather has proposed that while community goals may be important to the eventual success of a merger, institutional goals dominate in the early stages. ${ }^{2}$ These survey results support this proposition.

Most respondents to the initial survey believed that expectations had been met somewhat. No expectations had not been met at all, but neither had any been met in full. In all cases realization of benefits has 
fallen short of expectations. This is certainly in part due to the timing of the initial survey, i.e. in the middle of the merger process.

In the follow-up survey, persons indicated in most cases that expectations had been met more completely than in the initial survey. Still, little change over time was noted in improved organization of services, which has still fallen short of expectations by the largest margin. Ratings of improved health status, higher quality staff, services more accessible, higher quality care and more services available indicate that expectations for these factors have been essentially met. Ratings of perceived lowering of prices of services, although a very minor goal, was unchanged, and was the only measure to score lower by those responding to both surveys. Respondents to the follow-up were in greater agreement with each other as to the extent of benefits achieved, as evidenced by the uniformly lower standard deviations.

For most questions, there were no significant or substantial differences in responses across lines of affiliation. The only exception concerned how expectations have been met so far in the initial survey. Outsiders were significantly less likely to feel that their expectations, overall, had been met at that point in time as compared to persons affiliated with either of the merging organizations $(2.3$ vs. $3.5, \mathrm{p}<.001)$. By the time of the follow-up, however, the differences disappeared and outsiders were just as likely to feel that their expectations had been met.

\section{DISCUSSION}

These survey results suggest that community leaders had generally consistent impressions of the process and results of the merger. Most community leaders believe that a common philosophy and preserving community-based services were the most important factors in getting the merger started, and that a few key individuals were instrumental in continuing the process. The results further suggest that despite the broad set of goals of the project, most community leaders had modest expectations for changes resulting from the merger. Follow-up responses indicate that these expectations were met in most cases.

Since mergers of this sort may be a source of social and economic viability for rural health centers, paying attention to the views of community leaders may engender the support needed for a successful merger. Understanding the philosophy behind rural health services and obtaining the support of a few key individuals are important aspects to getting the merger process started and sustained. And finally, commu- 


\section{nication of the process and proposed benefits to community leaders can assist the formation of realistic expectations which can be achieved.}

\section{REFERENCES}

1. Whitehead, CJ, Blair, JD, Smith, RR, et al.: Stakeholder supportiveness and strategic vulnerability: implications for competitive strategy in the HMO industry. Health Care Management Review, 14:65-76, 1989.

2. Starkweather, DB: Mergers in the Making. Ann Arbor, MI: Health Administration Press, 1981.

3. Ricketts, TC, Konrad, TR, Stein, JS and DeFriese, GH: Population ecology and health policy analysis: the case of rural primary care centers. Medical Care Review, 44:345-374, 1987.

4. Sheps, CG, Wagner, EH, Schonfeld, WH, et al: An evaluation of subsidized rural primary care programs I: a typology of practice organizations. American Journal of Public Health, 73:38-49, 1983.

5. Prindaville, GM, Sidwell, LH and Milner, DE: Integrating primary health care and mental health services-a successful rural linkage. Public Health Reports, 98:67-72, 1983.

6. Smith, HL and Reid, RA: Integrating hospice and home health services: analysis of strategic factors. Home Health Care Services Quarterly, 8:87-102, 1987.

7. Cameron, KS: Critical questions: assessing organizational effectiveness. Organizational $D y-$ namics, 9:66-80, 1980.

8. Reid, RA and Smith, HL: Integrating rural health care systems: managerial implications for design and implementation. Journal of Ambulatory Care Management, 7:13-28, 1984.

9. Ashby, J: Management and community factors affecting the financial viability of rural health initiative sites. Joumal of Ambulatory Care Management, 4:1-13, 1981.

10. Banahan, B and Sharpe, T: Evaluations of the use of rural health clinics: knowledgre, attitudes and behaviors of consumers. Public Health Reports, 97:261-268, 1982.

11. Sardell, A: The U.S. Experiment in Social Medicine: The Community Health Center Program, 1965-1986. Pittsburgh, PA: University of Pittsburgh Press, 1988.

12. Ricketts, TC, Wagner, EH and Konrad, TR: An evaluation of subsidized rural primary care programs II: the environmental contexts. American Journal of Public Health, 73:406-413, 1983.

13. Joint Rural Task Force of the National Association of Community Health Centers and the National Rural Health Association: Community health centers and the rural economy: the struggle for survival, 1988.

14. Wood, JB, Hughes, RG and Estes, CL: Community health centers and the elderly: a potential new alliance. Joumal of Community Health, $11: 137-146,1986$.

15. Deprez, RD, Pennell, BE and Libby, MA: The substitutability of outpatient primary care in rural community health centers for inpatient hospital care. Health Services Research, 22:207. $233,1987$.

16. Snef, JF: The option to refuse: a tool for evaluating nonresponse to mailed surveys. Evaluation Review, 13:775-781, 1987.

17. Reid, RA, Bartlett, EE and Kozoll, R: Implementation of the health center concept in a rural community: a case study. Journal of Community Health, 7:57-66, 1981. 